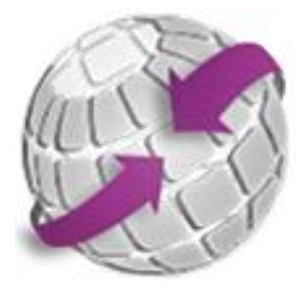

\title{
The Dynamics of ICT Infrastructure, Innovation, Globalization, and Economic Growth in OECD Countries: New Insight from a Panel Investigation
}

\author{
Meta Ayu Kurniawati \\ Ph.D Student, Graduate School of International Relations \\ Ritsumeikan University, Japan
}

\begin{abstract}
The rapid development of information and communication technology (ICT) over the last decade has enabled heterogeneous economic sectors to be more integrated, leading to a significant effect on nation's growth across OECD countries. The objective of this study is to estimate the short-run and long-run inter-linkages among ICT, innovation technology, globalization, and economic growth for the period 1996-2017 in OECD countries. The principal component analysis (PCA) is utilized construct ICT and innovation indices and follow up by employing the panel cointegration test, PMG, FMOLS, and DOLS as sophisticated estimation techniques, panel Granger causality, and forecast error variance decomposition to examine the robustness of the causal association in the findings. The empirical results herein suggest that ICT, innovation, and globalization positively contribute to economic growth, while the causality findings reveal strong endogenous relationships among both ICT mobile and internet use, innovation development, globalization, and economic growth in both the short run and long run. The findings further imply that OECD countries have yet to promote economic growth from ICT infrastructure expansion, the enlargement of technology innovation, and the spread of globalization. Therefore, one particular policy recommendation is to reinforce the investment and establishment of a strong ICT infrastructure as well as innovation technology in order to create sustained economic growth in this progressively interconnected world.
\end{abstract}

Keywords: ICT; innovation; globalization; economic growth; panel data analysis; panel cointegration; Granger causality; forecast-error variance decomposition 